\title{
PANEL DISCUSSION ON THE ROLE OF MODELING AND SIMULATION IN BUSINESS PROCESS REENGINEERING
}

\author{
Anthony Levas, Chair \\ IBM T.J. Watson Research Center \\ P.O. Box 218 \\ Yorktown Heights, New York, 10598, U.S.A \\ Pramod Jain \\ Innovative Decision Technologies \\ 400 East Randolf, Suite 2409 \\ Chicago, Illinois 60601, U.S.A.
}

\begin{abstract}
Modeling and Simulation are important technologies that can be applied to Business Process Reengineering (BPR). Dynamic process models afford the anal$y$ sis of alternative process scenarios through simulation by providing quantitative process metrics such as cost, cycle time, serviceability and resource utilization. These metrics form the basis for evaluating alternatives and selecting the most promising scenario for implementation. Tradeoffs can be made on the basis of measurements as opposed to intuition, resulting in more informed busin..ss decisions. This paper will summarize the ideas that will be presented in a panel discussion session on the role of modeling and simulation in Business Process Reengineering. Each panelist will represent a different perspective: 1) a theoretical view, 2) a BPR practitioner's view and 3) a software system view. The objective of this session is to highlight key issues in modeling and simulation of business processes from each of these perspectives and to motivate research and tool development in this area.
\end{abstract}

\section{INTRODUCTION}

In today's competitive business environment companies are looking closely at ways to increase their efficiency by reducing cost, while providing the products and services that customers want, whon thry want them. Business Process Reengineering (BPR) is an approach that is most often used to radically alter the processes of a company and generate new and better ways to run a business. Recent developments in the computer industry have made powerful computing machinery and sophisticated software avail-

\author{
Stowe Boyd \\ Work Mrdia \\ 209 Elden Street, Suite 202 \\ Herndon, Virginia 22070, U.S.A. \\ William A. Tulskie \\ IBM T.J. Watson Research Center \\ P.O. Box 218 \\ Yorktown Heights, New York, 10598, U.S.A.
}

able to the consulting practitioner. They no longer need to rely on the old pencil and paper approach. They have, at their disposal, highly developed modeling and analysis tools and methodologies to assist in the descriptive and behavioral analysis of the systems they study. These tools are not back in the office but come in the form of laptop computers loaded with complex software. This paper will highlight current issues in using and developing tools and methodologies for business process modeling and simulation.

Three perspectives will be presented. A theoretical perspective will outline current and emerging methodologies and techniques that are relevant and will provide a framework from which to view developments in this area. A practitioner's view will highlight the requirements for tools and techniques from the context of a practicing consultant. A software system perspective will provide a systems view of integrated tools that assist the user in the various activities he performs. Our objective is to motivate research and development in tools and modeling methodologies that are relevant to business process reengineering.

\section{A THEORETICAL PERSPECTIVE}

\section{Stowe Boyd}

We are witnesses to an enormous change in the world of business, and one of the most obvious manifestations of that change is the rise of BPR. In the past five years, BPR has become the keystone of modern strategic planning.

I have argued in other writings that BPR is not the driver of these enormous shifts in our social fabric, but instead "business engineering is best viewed as a 
sert of survival skills, an adaptation to these changes, rather than a science; and it will come as no surprise that many of these skills involve application of various forms of information technology. What may be unexpected is the degree to which offective use of these technologies will requir rethinking fundamental concepts of business and work" (Boyd 1995a, 1995b, 1995c, Bridges 1994).

In this paper I will limit the scope of my ruminations to the critical area of business process modeling and analysis, and to suggest ways that the thinking and work of various innovators will perhaps come t. impact us all in the future.

\subsection{Future Shift to Business Process}

Rummler and Brache (1988), in their book Improving Performance, noted that a business manager, if asked to draw a picture of his or her business, would likely sketch the traditional organization chart. As an outgrowth of the shift toward the process-centered enterprise, we would be more likely to see some form of process presentation, as recently happened to me, as I lunched with representatives from a large industrial firm involved in a major reengineering effort. I call this the Rummler/Brache test. Rummler and Brache (1988) noted "the picture inevitably shows the vertical reporting relationships of a series of functions." The authors go on to note many things of interest missing from this typical picture: customers, suppliers, products and services, and the flow of work to make, market and carry products and services to customers.

So the traditional view has been overthrown to some extent, and the primary model for the business is no longer based solely on an unchanging organization structure where the principal relationship between parts is authoritarian reporting relationships. Today, we see that this industrial-era model is passing from the scene, and is being replaced by a new paradigm, one where customers, suppliers, the flow of work, and the interactions of staff supplant the organizational chart.

\subsection{Secondary Effects}

There is a beneficial secondary effect of the rise of process. Those involved in business today are acquiring a new language for thinking and talking about business. Benjamin Whorf, the well-known linguist, argued that we cannot conceive of ideas that cannot be represented in a language; moreover, learning new languages allows us to think differently. A lingua franca of business process is growing up around us, with immediate impact on all those who learn and use it. There is a Tower of Babel effect regarding process-literally hundreds or thousands of languages, of all descriptions. We can anticipate the convergence in the near term to a handful of profitable and widely accepted forms. The object-oriented approach, having risen to prominence in software modcling, is of great interest here. The work of Jacobson and his colleagues, and Tom Malone and the Sloan School Center for Coordination Research at MIT is ispecially relevant. I anticipate the emergence of an object-oriented denotation for process that will become the dominant representation. The benefits of other approaches, such as flowchart and workflow derived techniques, will be incorporated into the $\mathrm{OO}$ approaches.

Another secondary effect arising from the spread of BPR is a shift in the purposes of modeling and analysis. Today, we seem to be most concerned with minimizing labor and other resources applied in processes. The logical conclusion of such optimization is equivalent to "speeding up the assembly line." However, we are beginning to understand that the business is not just the production and marketing of products, but shifting to a new economic currency, based on the exploitation of information. This requires building an organization that can adapt to great and unpredictable change. Speeding the line can be highly counterproductive, since the process participants may be kept from other activities, such as discovery or learning, which are critical to the continued and future success of the firm.

Hamel and Prahalad (1995) have made cogent arguments regarding process innovation as the basis of future competitive advantage; Davenport (1993) has authored a best-selling work entitled process innovation. Keen and Knapp's work on Process Investment is an economic approach to process modeling that supports Hamel and Prahalad's theoretical arguments with tactical, down-to-earth techniques. From these starting points, we can expect that the next stage of process modeling and analysis will be more focused on the interaction between the short cycle (sales and production), medium cycle (marketing and customer interaction), and long cycle (invention, innovation, research) processes of the firm. And we will see increasing attention on process linkage and the impact of changes in the short cycles on the most critical, long cycle processes.

\subsection{Tertiary effects}

Marshall McLuhan (1964) presaged the effects of "automation" on the nature of work over thirty years ago. As I have written elsewhere (Boyd 1995d), 
McLuhan's book Understanding Media discusses the cultural revolution that information technology is causing, where, the value of an individual is not measured in units/hour, or dollars/quarter, but in their contribution to future success. Currently, we have what I call top-down (autocratic) process representation as typified by flowcharting, being replaced by team-based (egalitarian) process modeling approaches.

Just as we are seeing a move to "narrowcasting" and "arrowcasting" in new marketing, we will need to move toward process representation and analysis that seeks to capture the unique skills and capabilities of each individual, rather than abstracting in generalized roles like "payroll clerk" or "customer." This I call participant-based process modeling. Some of the ideas behind coordination theorists Malone, Winograd, and Flores lead in this direction; also the work of Marvin Mannheim (Kellogg School, Northwestern University) points in this direction.

\section{A PRACTITIONER'S PERSPECTIVE}

\section{Pramod Jain}

Simulation is an essential analysis tool for business process redesign. It enables a process redesigner to model, visualize, understand, experiment with, and evaluate current and redesigned processes.

\subsection{The Need for Simulation}

Engineering disciplines have well established methods for analysis. These analytical methods are predictive in nature. Although the discipline of business processes is quite different from the traditional engineering disciplines, the need for predictive analysis tools is unquestionable. For business processes simulation comes closest to being a predictive analysis tool. One of the biggest business benefit of such an analysis tool is that it saves a business time and money-the effect of process changes can be tested, and an optimal process can be found on the computer inexpensively compared to trying it out on a business itself. In addition, simulation can be used to perform cost-benefits analysis under multiple business scenarios.

Simulation creates a dynamic model of the current or redesigned business process that mirrors (as close as the modeler would like) the actual process. To build such a model, modelers are forced to specify details that they would not have otherwise thought of. Refinement and validation of the simulation model for the current process by comparing the actual output with the simulation generated output, leads to an in- sightful understanding of the process. Modelers carry this insight over to the redesigned business process.

Simulation with animation tools is a powerful communication vehicle to convince management and the team that will implement the change. To a person not intimately involved with the simulation effort, it gives a visual representation of the current and new processes. A simulation model therefore greatly facilitates selling and buy-in of the new process.

\subsection{Current Simulation Products and BPR}

BPR efforts typically start with a flow charting tool that has no or limited simulation capabilities. There is a need for effortlessly taking a business process from a flow chart to one that is simulatable. The intermediate steps will involve soliciting details required for simulation from the modeler about each of the process objects. The onus should be on the tool to ask for information from the user, rather than on the user to completely specify the simulation model up front.

\subsection{Methodology}

In addition to the usual steps of methodology, an overarching consideration should be a clear specification of the benefits to be achieved through simulation and a plan to achieve these benefits. To accomplish this, the project must attach to each major milestone of a simulation project, a business benefit that the company will derive. That is, the goal of a milestone should be to achieve a quantified business benefits, for example, reduction in work in process inventory by 10 percent. This is in contrast to a goal like the ability to simulate 75 percent of the products and 60 percent of the resources.

\subsection{Risks}

Analysis Paralysis: Business process redesign is about creating new processes that provide an organization the capability to achieve its objectives. Simulation is a tool to achieve this, it is not an end in itself. Often creating the most detailed as-is model, interfacing with all the data sources and other exercises of little value, are conducted to be complete and thorough. This is one of the risks.

One of the biggest risks is creation of a "to-be" model based solely on tweeking of the simulation model of an "as-is" model. In most cases such an approach will lead to a myopic view of BPR, it will certainly not lead to the most creative redesigns. Simulation is most useful for comparing as-is and to-be models, and validating and ensuring the completeness 
of the to-lue process model. Beyond this, simulation has limited utility in creating a to-be model.

There is the classic dilemma: you can keep track of aspects that you know are not modeled, versus aspects that you don't know about, and obviously are not modeled. One way to overcome this ignorance is through modeling of multiple scenarios and comparison of the results with expected outcomes.

From an analytical stand point, business process redesigners that have little background in statistics or simulation do not model variability in demand, processing units, or any other object of simulation. In most businesses process parameters determined based on deterministic analysis are of limited utility.

From a data stand point, process designers are tempted to design and run the simulation model with only one data set. Process parameters are determined and fine tuned using this single data set. Of course the pattern in the data set is never going to repeat. Therefore a to-be process must be simulated with multiple data sets that cover the entire spectrum. For example high to low mean demand, high to low demand variance, etc.

\subsection{Summary}

Simulation is a powerful predictive tool for business process redesign. Its capabilities to prescribe to-be process models is limited.

\section{A SYSTEMS PERSPECTIVE}

\section{William Tulskie}

Consultants are involved in many different tasks during the course of a reengineering engagement. These range from selling the engagement to the customer, understanding and documenting the processes and problems, evaluating alternative process implementations, recommending and convincing the customer to implement a particular solution, advising during the implementation phase and finally participating in incremental improvements throughout the life cycle of the reengineered process. An integrated software environment that assists reengineering practioners throughout this process would be an extremely valuable tool which would reduce the time spent and result in better performance of each of the activities. This section will outline some of the key features and functions that such a system would provide.

Advances in hardware technology have put powerful tools literally in the laps of users. Today, fast CPU's with lots of memory and disk space are interconnected to LAN's facilitating the sharing of infor- mation and off loading of computation to even more powerful machines. This affords the creation and sharing of large, sophisticated models and their analysis using simulation, optimization and other techniques. This performance trend is expected to continue, making integrated systems of the type described below possible.

\subsection{Model Generation}

An essential feature of such a system is ease of use. Each activity that is to be performed by the user should be supported by some features of the system. Easily capturing descriptive as well as behavioral characteristics of a process as well as qualitative and quantitative information in a single model is important. It provides a unified representation of the process which can be analyzed from different views. Creation of alternative process scenarios can be facilitated through an expert advisor facility that allows the user to browse existing models that have some similarity to the problem at hand, providing insight into solving the user's problem. Other expert advisors may criticize existing models based on simulation, queuing analysis or other techniques and recommend modifications resulting in improvements to the model under study. An expert experiment managing facility could assist in the designing of experiments, running the experiments, and presenting the results. Multiple replications and different experimental scenarios could be farmed out to processors that are idle during off shifts.

\subsection{Visualization}

Visualization of models is equally important. New ways of presenting and navigating through the process map, revealing their associated information and material flow, resources used by activities, and control policies that govern their behavior are very useful in obtaining a shared understanding of existing and hypothetical processes. This shared understanding is important between colleagues on the same interdisciplinary team, client/consultant relationships and as a teaching tool for people learning and analyzing the process. Presentation of analytical results across different process scenarios is also very important in the analytical phase of a project. Novel visualization techniques provided through animation or browsing of the model and analytical results clearly play a significant role in helping the user understand the process. 


\subsection{Modeling Elements}

The modeling concepts or building blocks that a system provides are the key to the fidelity and complexity of the models that can be created. Users require powerful basic building blocks that afford the representation of the complex behavior which is evident in real world processes. Preferably, this can be captured by the user through the parameterization of some existing concept without resorting to writing code. Creating powerful resource models that describe the behavior of working people, as well as machines, also pose significant challenges. The ability to model complex policies for selecting, postponing and resuming work, and expressing constraints for groups of resources cooperating in a task is essential for modeling today's workplace. The ability of the system to easily use the representation of the objects in the model for reasoning is another important feature of the system. This allows the model to serve as a basis for different kinds of analyses.

\subsection{Libraries}

Modeling concepts can be generic, that is, generally useful in many domains or can be very specific to one domain. For example, the concept of assembly is useful for the manufacturing industry but probably not relevant to the insurance industry. Libraries of domain-specific building blocks arranged by industry or area can provide a powerful basis for building models in specific arenas. In addition, libraries of completed models can serve as a repository for the intellectual capital of an organization. Proper management of these libraries, such as sharing, storage and retrieval, are important issues for an integrated system. The combination of existing models to create a larger enterprise model is also important. These enterprise models can be further aggregated to model global inter-enterprise behavior.

\subsection{System Issues}

The aggregation of models highlights several new problems such as scalability and model merging. The scalability issue is related to performance and robustness of the underlying system. Many systems are adequate for small to medium scale problems but run into difficulties with larger problems. It is critical for the base system to be able to handle large problems. Merging models presents additional considerations such as the conflict of loading processes or resources with the same name from different models and determining which one to use. A related issue is shared access to models and concurrent development of a model by several individuals. These are important issues for robust reengineering software systems.

The ability to pass data and call out to optimization, scheduling and other packages is also very important. This highlights the issue of interoperability between the reengineered system and systems that are external to it.

\subsection{Conclusion}

Integrated software systems designed for the reengineering practitioner can have a significant impact on the efficiency with which engagements are executed and upon the quality of the results that are provided. Systems that have some of the features described in this section are already beginning to emerge. It is very exciting to observe the changes that have taken place and to participate in the development of this area. Advanced reengineering tools should play a significant role in the future reengineering of our business and social organizations.

\section{REFERENCES}

Boyd, S. 1995a. Work in Progress: An Introduction to Business Process Reengineering. In Proceedings $B P R /$ Workflow. Orlando FL.

Boyd, S. 1995b. Reworking Work. Working paper.

Boyd, S. 1995c. Misunderstanding Understanding Media. Work Talk, 1(2).

Boyd, S. 1995d. Work Software. Enterprise Reengineering, March.

Bridges, W. 1994. JobShift. Addison-Wesley.

Davenport, T. 1993. Process Innovation: Reengineering Work Through Information Technology. Harvard Business School Press

Hamel, G. and (. K. Prahalad. 1995. Competing for the Future. MIT Press.

McLuhan, M. 1964. Understanding Media: The Extensions of a Man. MIT Press.

Rummler, G. and A. Brache. 1988. Improving Performance. Jossey.

\section{AUTHOR BIOGRAPHIES}

STOWE BOYD is President of Work Media, an innovative media and consulting firm, with a primary focus on the work software industry such as software for business engineering, work flow, groupware, and work group computing. Clients include BIS Strategic Decisions, an international market research firm, where Work Media led a 1995 comprehensive survey of the leading workflow products. Stowe Boyd is a well-known entrepreneur who has been involved in 
the reengineering and revitalization of several software firms. He is editor of Work Talk, a web ezine on the work software industry. He is a frequent speaker on information technology and business engineering: invited speaker at Business Process and Workflow '94 and '95, ProjectWorld '95, International Workflow Conference November '95 (Vienna), and program chair of Tools and Methods for Business Engineering in May 1995 (Washington, D.C.)

PRAMOD JAIN is the President of Innovative Decision Technologies, Inc. (INDENT), a business process and decision systems consulting company. One of the areas of focus is supply chain management. Prior to INDENT, Pramod was a scientist at the Center for Strategic Technology Research of Andersen Consulting in Chicago. There he led the business reengineering research group. Pramod has a Ph.D. from the University of California at Berkeley. Pramod has worked extensively with simulation for a wide range of purposes including validating stochastic optimization algorithms, modeling of supply chain, and business process redesign.

ANTHONY LEVAS is an Advisory Programmer in the Manufacturing Research Department at the IBM T.J. Watson Research Center, Yorktown Heights, N.Y. He received a Master's Degree in Computer Science from the University of Connecticut at Stoors. His research interests are in Human Cognition, Knowledge Representation, Robotics, and Modeling and Simulation. Mr. Levas is currently the project leader for the Business Process Modeling and Analysis Tool (BPMAT) which is under development at IBM Research.

WILLIAM TULSKIE is a Senior Engineer in the Manufacturing Research Department at the IBM T.J. Watson Research Center, Yorktown Heights, N.Y. He received a BSEE from Drexel University. He was awarded an MS in Engineering and the title Moore Fellow in the Management of Technology from the University of Pennsylvania. He has worked in research and production engineering while at Litton Systems, and in marketing and systems engineering at IBM. His research interests include business process modeling and simulation, supply chain management, and product life cycles and substitution dynamics. 